American Journal of Applied Sciences 8 (2): 147-155, 2011

ISSN 1546-9239

(C) 2010 Science Publications

\title{
Positron Annihilation Study on Nickel and Iron Nano-Particles in Natural Rubber Composites
}

\author{
Emad Hassan Aly \\ Department of Physics, Faculty of Science, Ain Shams University, \\ P.O. Box 11566, Abbassia, Cairo, Egypt
}

\begin{abstract}
Problem statement: The effect of $\mathrm{Ni}$ and $\mathrm{Fe}$ nano-particles as a filler on the free volume properties Of Natural Rubber (NR) was studied using Positron Annihilation Lifetime Spectroscopy (PALS). Approach: The PAL measurements revealed that the free volume properties are strongly affected by the amount and type of filler. Results: Particularly speaking, the free volume fraction dramatically decreased by increasing the filler content. Besides, the addition of nano-prticles created new positron trapping sites at filler-rubber interfaces. Furthermore, correlations were made between the free volume hole sizes $\left(\mathrm{V}_{\mathrm{h}}\right)$ and each of the mechanical and electrical properties successively. A negative correlation was observed between $\mathrm{V}_{\mathrm{h}}$ and hardness in the Ni-rubber composites while a positive counterpart was found in the case of Fe-rubber composites. Finally, the polarity of the fillers, being higher than that of the rubber itself, leads to an increase in electrical parameters and an inhibition of o-Ps formation. Conclusion: These results indicate that the investigated composites are considered to be insulating materials as their conductivity values are in the order of an insulator range.
\end{abstract}

Key words: Free volume, crosslinking density, tensile strength, dielectric loss, Natural Rubber (NR), Positron Annihilation Lifetime Spectroscopy (PALS), Rubber Ferrite Composites (RFC), nanoscopic inorganic, polymer nanocomposites, Polymer Bonded Magnets (PBMs)

\section{INTRODUCTION}

The production of polymer nanocomposites is an essential feature of polymer nanotechnology. They represent a new alternative to conventionally filled polymers. Polymer nanocomposites are materials in which nanoscopic inorganic particles dispersed in an organic polymer matrix in order to considerably develop the performance of the mechanical and thermal properties of the polymer (Chatkaew et al., 2010). Because of their nanometer sizes, nano-fillers $(0.1-200$ $\mathrm{nm}$ length scale) can increase the modulus, strength, toughness, resistance to chemical attack, resistance to thermal degradation, flammability resistance and dimensional stability of polymeric materials. Polymer materials have been filled with several inorganic compounds (Al, $\mathrm{Fe}, \mathrm{SiO}_{2}$ and Carbon black) (Hussain et al., 2006). Inorganic nanoparticles have gained acceptance as possible reinforcing structures because of their low cost and ease of fabrication. As a result of inserting the nanometric inorganic compounds, the properties of polymers develop and consequently this has countless applications depending upon the inorganic material present in the polymers (Bolonkin, 2009). Polymer nanocomposites containing ferrites are gradually replacing usual ceramic magnetic materials for the reason of their mould ability and lessening in price. They are also promising materials for microwave absorbers, sensors and other aerospace applications. These bendable magnets or rubber ferrite composites are possible by the integration of magnetic powders in various elastomer matrices (Makled et al., 2005).

By selecting a suitable polymer matrix, magnetic fillers can be integrated to form a composite of needed mechanical, magnetic and dielectric properties. Natural Rubber (NR) is one of the significant elastomers and chosen as the matrix for mixing the magnetic fillers. This picking is also due to the fact that NR is inexpensive and plentiful as a natural supply. These composites can be used as flexible magnets and the mouldability of rubber gives a high extent of freedom in terms of form and size. There are reports on the studies of electrical properties of composites based on natural rubber with ferrite particles as fillers (Sindhu et al., 2002). Because ceramic magnetic materials cannot be moulded into multifarious shapes, Rubber Ferrite Composites (RFC) can substitute them where the shape is an essential principle. Many useful technological applications can be based on composites of elastomers materials primarily because of their flexibility and mouldability (Anantharaman et al., 1999). 
It is well recognized that the dielectric properties of an insulating host material can be modified to be conducting or semi-conducting by dispersing electrically conducting filler particles in the host material (Tanaka et al., 2004). Magnetic fillers as well could be incorporated into rubber matrices to convey magnetic property to the host and such fillers can be metal particles or magnetic oxides like ferrites (Zhang et al., 2006). Ferromagnetic iron, nickel or cobalt particles are chosen as metallic magnetic filler materials (Jamal et al., 2009). Each material has exclusive properties that make it more appropriate for the selected applications such as magnetic strength, resistance to demagnetization, physical strength and flexibility (Khor et al., 2009). Nickel, being metallic can alter the dielectric properties of rubber and at the same time, being ferromagnetic can impart high magnetic permeability to the composites. Ferrites stay one of the most valuable magnetic materials that are ever revealed because of their easy synthesis, low-cost and participation in a wide range of technological applications (Cullity, 1972). So, they are still extensively used wherever the product price is considered more than magnetic performance. Concurrently, they are preferred even though they have less magnetic strength than rare earth magnets. The advantages of Polymer Bonded Magnets (PBMs) over their metallic and ceramic counterparts include low weight and cost, resistance to corrosion, simplicity of machining and forming and ability of high production rates (Otaigbe et al., 1999). The mechanical properties of PBMs depend strongly on properties of polymer matrix, magnetic fillers and interfacial condition between the components (Xiao and Otaigbe, 2000). In addition, the surface area of the filler is the primary factor to control the mean distance between particles. The higher the surface area, the shorter the interaggregate distance would be.

Assessment of the magnetic and dielectric properties of metal elastomer composites is important to assess valuable information regarding the matrix filler interaction, dispersion of filler and percolation threshold that are significant in determining the gross physical properties of the composites (Ali et al., 2010). There are many factors which control the dielectric and conducting properties of the composites (Elimat et al., 2008). The most essential of these is the ratio of the filler particles to the host material. At lower volume ratios, the composites are good dielectric materials, but the conductivity of the composites can increase piercingly at some critical value of the volume ratio. This is due to the formation of conductive paths at the percolation threshold of the filler particles (Dang et al.,
2004). However, within the percolation threshold, these materials are good insulators and the volume ratios of the filler material can adjust their dielectric properties.

Positron Annihilation Spectroscopy (PAS) is an ideal non-destructive method for the detailed study of polymers and polymers with fillers have been discussed in detail (Jean, 1990). The primary experimental Positron annihilation technique used in this research is positron annihilation lifetime spectroscopy (PALS, one of the three techniques in the PAS family).

PALS has been widely applied to the study of materials (Puska and Nieminen, 1994). PALS has emerged as a powerful tool for measuring the freevolume size in various materials (Dull et al., 2001). The free volume concept plays an important role in polymer research and is widely used to describe and explain the behavior of physical properties such as glass transition temperature, viscosity and physical aging. Free volume is affected by the blending of polymers, age and addition of various fillers. PALS is an effective method in detecting the free volume space considering the fact that the Positronium (Ps) atoms are formed and localized in the nanometer-scale holes in various materials. PALS measures the o-Ps lifetime distribution in the sample, which is particularly related to the freevolume size on the scale of 1-10 $\mathrm{nm}$. Moreover, the intensity of Ps annihilation correlates with the amount of the free volume or the number of voids (Schrader and Jean, 1988). The usefulness of positron annihilation spectroscopy in materials analysis depends on the correlation of a positron parameter such as intensity or lifetime and other important physical and chemical properties of the samples. Corresponding to the mutual spin orientations (anti-parallel and parallel) of the consisting particles, Ps exists in two states: para-Ps (pPs) with anti-parallel spins ( $\downarrow)$ and ortho-Ps (o-Ps) with parallel spins ( $\uparrow)$. The intrinsic lifetimes of p-Ps and o-Ps in vacuum are 0.125 and 142 ns respectively (Puska and Nieminen, 1994). In molecular materials such as polymers, the o-Ps undergoes the process of pick-off annihilation with surrounding electrons and its positron annihilates with an electron from the surrounding media (the so-called pick-off process). Therefore, the o-Ps lifetime is shortened to some ns (fast $\uparrow \downarrow$ annihilation process) while the p-Ps lifetime remains practically unchanged due to its high annihilation decay rate. By detecting the fate of o-Ps, specific information about the free-volume structure of the polymer can be obtained because Ps has an extreme sensitivity to holes or regions of low electron density in the material where it is localized. It has been shown that the lifetime, $\tau_{3}$ of o-Ps, well correlates with the size of the free-volume holes (Schrader and Jean, 1988). Several polymers such as polystyrene, polyethylene, 
poly (methyl methacrylate), polytetraflourothylene, polycarbonate, poly(vinilydene fluoride) have been studied by using PAL (Faupel et al., 2004).

El-Nashar et al. (2006) have studied the mechanical, electrical and magnetic properties of Natural Rubber (NR) composites containing iron or nickel nano-particles at different percentage varying from 0-120 phr. They have found out that the optimum concentration of magnetic fillers in NR is $30 \mathrm{phr}$, which improves the mechanical and electrical properties.

As a continuation of El-Nashar et al. (2009) study, this study investigates the effect of $\mathrm{Ni}$ and $\mathrm{Fe}$ nanoparticles filler on free volume properties of natural rubber. This study also aims at establishing a correlation between each of the mechanical and electrical properties of nanoparticles-rubber composites with microstructure free volume properties as a function of phr filler content.

\section{MATERIALS AND METHODS}

Materials: The composites based on natural rubber are produced in Maliysia under the trade name RSS-1. The composites are Ribbed smoked sheets with a specific gravity $0.913+0.005$ and Mooney viscosity at $100^{\circ} \mathrm{C}=$ $60-90 \mathrm{r}$ and glass transition temperature $\mathrm{T}_{\mathrm{g}}=-75^{\circ} \mathrm{C}$. The composites contain a fixed content of natural rubber (100 phr, phr = parts by weight per hundred parts of rubber) and other chemicals such as sulfur (1.5 phr), zinc oxide (5phr), stearic acid (1 phr), n-Cyclohexyl-2Benzothiazole Sulphenamide (CBS) (0.6 phr) and Phenyl- $\beta$-naphthyl Amine (PBN) (1 phr). The natural rubber composite is used as a host material in this study and filled with different ratios of iron $(\mathrm{Fe})$ with average particle size varying between 26 and $45 \mathrm{~nm}$ and nickel (Ni) with average particle size varying between $22 \mathrm{~nm}$ and $50 \mathrm{~nm}$. The formulations of the composites are given in (El-Nashar et al., 2009). The samples were prepared in Polymers and Pigments Department, National Research Centre, Cairo, Egypt.

Positron lifetime measurements: The Positron Lifetime Spectrometer consists of an EG\&G ORTEC fast-fast coincidence system (Urban-Klaehn and Quarles, 1999). The spectrometer is used to record all PAL spectra at room temperature. The time resolution (FWHM) of the conventional fast-fast coincidence system is about $270 \mathrm{ps}$ employing a ${ }^{60} \mathrm{Co}$ source. The positron source is prepared by depositing aqueous ${ }^{22} \mathrm{NaCl}$ with $20^{\circ} \mathrm{Ci}$ as a radioactive positron source on a $7 \mathrm{~mm}$-thick pure Kapton foil having a $1 \times 1 \mathrm{~cm}^{2}$ area. After drying, the foil is covered with an identical foil and the edges of the two foils are sealed with epoxy resin. The positron source is placed between the two identical pieces of the sample (sample-source-sample arrangement) for investigation. This sample-source sandwich is positioned between the two detectors of PALS to acquire the lifetime spectrum.

We analyze the lifetime spectra into three components using the LT program (Kansy, 2001). The fitting is for the set of the exponential components convoluted with the instrumental resolution curve. We use the feature of the LT program that allows mixed analysis: two short-lived components are assumed as purely exponential with a discrete decay constant $\mathrm{k}$ and a long-lived component due to pick-off o-Ps annihilation, as continuous $\mathrm{k}$ distributions approximated by log-Gaussian distribution. Each component corresponds to a particular state from which the positron annihilates. Therefore, instead of the three discrete lifetime components, a continuous distribution of the inverse of the longest lifetime $\left(1 / \tau_{\mathrm{o}-\mathrm{Ps}}\right)$ can be obtained by using the LT program, where $\tau_{\mathrm{o}-\mathrm{Ps}}$ is $\tau_{3}$ in this distribution. The advantage of using LT is that one can analyze spectra with normal statistics of $10^{6}$ counts and only one additional parameter $\sigma$, the "width" of the lifetime log-normal distribution (Williams et al., 1995). Through $\sigma$, the mean lifetimes and their dispersions can be calculated. Lifetime spectra have conventionally been described as a sum of three decay components like that given in the Eq. $\mathrm{S}(\mathrm{t})=\sum \mathrm{I}_{\mathrm{i}} \mathrm{P}_{\mathrm{i}}(\mathrm{t})$, $i=1,2,3, \ldots$.where $I_{i}$ is the relative intensity (fraction of annihilation events) of the $i_{\text {th }}$ component, $\sum I_{i}=1$. The function $\mathrm{P}_{\mathrm{i}}(\mathrm{t})$ gives the probability of a positron in the given state, $i$, annihilating in the time interval between $t$ and $\mathrm{t}+\delta \mathrm{t}$ after the birth of positron (Williams et al., 1995). Conventional analysis involves a non-linear least-squares fit of the equation: $\mathrm{S}_{\exp }(\mathrm{t})=$ $\mathrm{N}[\mathrm{S}(\mathrm{t}) \otimes \mathrm{R}(\mathrm{t})]+\mathrm{B}$ is used. While $\mathrm{R}(\mathrm{t})$ is the resolution function of the spectrometer, $\mathrm{N}$ is the total number of counts and B is a background count level. Usually in polymers, three lifetime components appear in the PALS spectra giving the best-fit $\chi^{2}<1.1$ and most reasonable standard deviation (Jean and Dai, 1993). They are attributed to the annihilation of $\mathrm{p}$-Ps atoms $\left(\tau_{1}\right)$, free positrons (not Ps) $\left(\tau_{2}\right)$ and o-Ps atoms $\left(\tau_{3}\right)$. pPs decays mainly via self annihilation with a characteristic lifetime in vacuum of about $0.125 \mathrm{~ns}$. The lifetime of o-Ps (142 ns in vacuum) decreases in matter, typically to low nanosecond range due to the pick-off annihilation process. The o-Ps localizes in the space between and along polymer chains and at chain ends (free volume holes) and the lifetime gives indication on the mean radii of these holes (Pethrick, 1997). If o-Ps is confined to the free volume holes in amorphous polymers, its lifetime is reduced to the range of $0.5-5$ 
ns. Besides, the characteristic lifetime of the pick-off annihilation process is highly sensitive to the size of these free-volume holes (Brandt, 1983).

The pick-off annihilation lifetime of the o-Ps can exhibit correlation to the size of the free-volume holes $\left(\mathrm{V}_{\mathrm{f}}\right)$ by a semi-empirical equation, proposed by Nakanishi and Jean according to the quantummechanical model of Tao later developed (Schrader and Jean, 1988). Significantly, $I_{3}$ is a relative measure of the number of free-volume holes in the amorphous region of polymer matrix. This semi-empirical equation assumes a spherical hole symmetry and proposes that oPs is a point particle in an infinite potential well, annihilating via pick-off in an electron-containing layer of thickness $\delta \mathrm{r}$. The expression correlates the free volume radius $\mathrm{R}$ (in $\mathrm{nm}$ ) and the o-Ps pick-off lifetime $\tau_{3}$ (in ns) (Schrader and Jean, 1988) is:

$$
\frac{1}{\tau_{3}}=2\left[1-\left(\frac{\mathrm{R}}{\mathrm{R}_{\mathrm{o}}}\right)+\left(\frac{1}{2 \pi}\right) \sin \left(\frac{2 \pi \mathrm{R}}{\mathrm{R}_{\mathrm{o}}}\right)\right]
$$

where, $\delta \mathrm{R}=\mathrm{R}_{0}-\mathrm{R}=0.1656 \mathrm{~nm}$ representing the thickness of the electron layer or the probability of overlap of the Ps wave function and electron wave function. Considering this value of $\mathrm{R}$, the free volume size $\left(V_{f}\right)$ is calculated as $V_{f}=(4 / 3) \pi R^{3}$. Then, the relative fractional free volume (f) is evaluated as the product of free volume $\left(\mathrm{V}_{\mathrm{f}}\right)$ and o-Ps intensity, $\mathrm{I}_{3}(\%)$ according to the following equation:

\section{$\mathrm{f}=\mathrm{CV}_{\mathrm{f}} \mathrm{I}_{3}$}

where, $\mathrm{C}$ is a coefficient constant.

In real systems, it is anticipated that the fitting process to discrete lifetimes will be something of a crude approximation as there is likely to be a distribution of hole radii giving a distribution of lifetimes. To account for this, the program LT9 (Kansy, 2001) is used to fit lifetimes $t_{i}$ with distributions, mimicking the hole size (and shape) distributions. Using LT9, the annihilation rates are assumed to be lognormally distributed; this choice of distribution is supported by previous analyses using CONTIN where a fully continuous distribution of lifetimes is allowed.

\section{RESULTS}

Figure 1a and $\mathrm{b}$ shows the change in $\tau_{3}$, which is a measure of the size of the free-volume hole $\left(\mathrm{V}_{\mathrm{f}}\right)$ of $\mathrm{Ni}$ / Fe-rubber composites set against the filler content (phr). The size of free-volume holes of Ni-rubber composites tends to decrease with increasing filler content as shown in Fig. 1a. In contrast, the free-volume hole size of Fe-rubber composites noticeably increases before
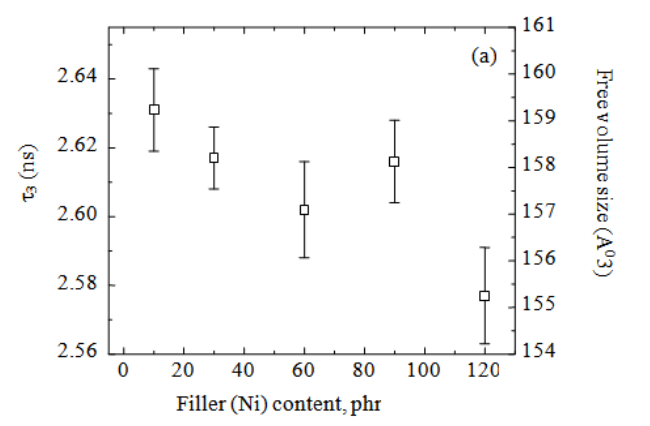

(a)

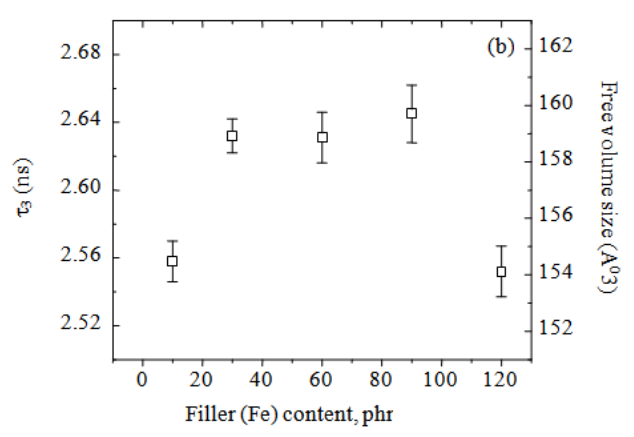

(b)

Fig. 1: $a$ and $b$ the change in $\tau_{3}$ as a measure of the size of the free-volume hole $\left(\mathrm{V}_{\mathrm{f}}\right)$ of $\mathrm{Ni} / \mathrm{Fe}$-rubber composites against the filler content (phr)

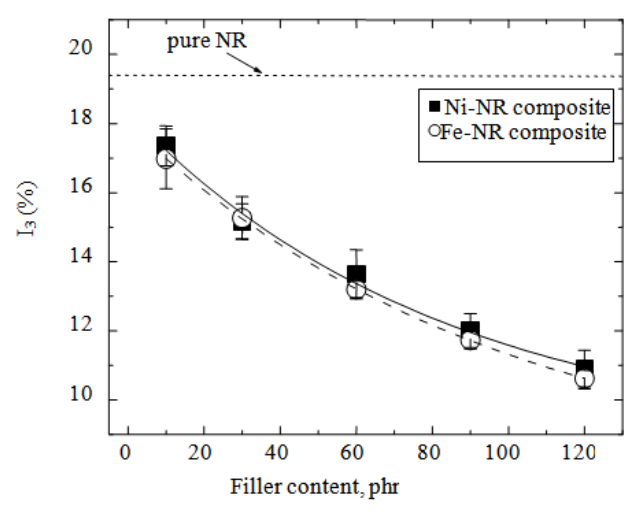

Fig. 2: The variation of $\mathrm{I}_{3}$ with the filler content in rubber

attaining constant values (in the range from $30-90 \mathrm{phr}$ ) and decreases at higher filler loading of Fe (Fig. 1b). The variation of $\mathrm{I}_{3}$, which measures the fraction of freevolume holes, as a function of filler content in rubber is highlighted in Fig.2.

The free volume holes size distributions in natural rubber, Ni-NR and Fe-NR composites are displayed in Fig. 3. In pure $\mathrm{NR}$, the average size of free volume holes $\left(\mathrm{V}_{\mathrm{h}}\right)$ is $160 \AA^{3}$. In Ni/Fe-NR composites, the 
Am. J. Applied Sci., 8 (2): 147-155, 2011

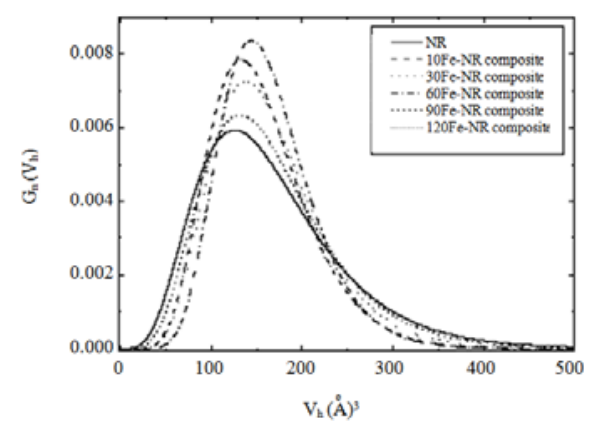

Fig. 3: The free volume holes size distributions in natural rubber, Ni-NR and Fe-NR composites

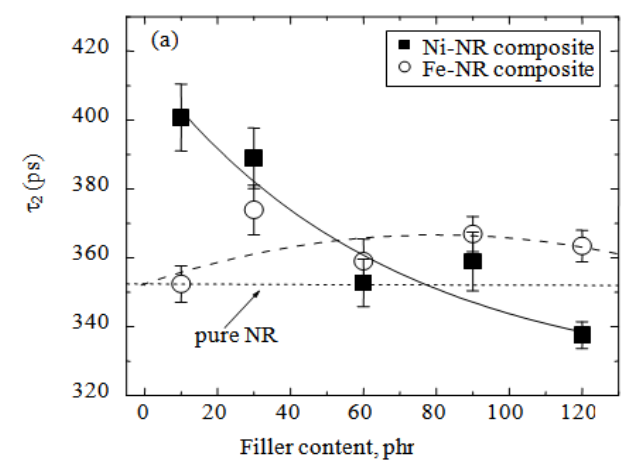

(a)

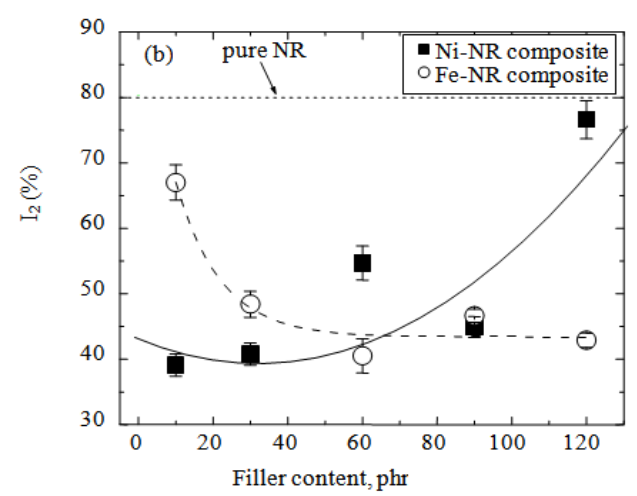

(b)

Fig. 4: $\mathrm{a}$ and $\mathrm{b}$ the variation of $\tau_{2}$ and $\mathrm{I}_{2}$ as a function of filler content

distributions shift to smaller free volume holes sizes as a function in filler content, which are ranging from about 159-155 $\AA^{3}$. The observed trends are consistent with the results obtained by the finite lifetime analysis (Fig. 1).

Figure $4 \mathrm{a}$ and $\mathrm{b}$ represents the variation of $\tau_{2}$ and $\mathrm{I}_{2}$ as a function of filler content which provides information on the defect changes in crystalline regions and amorphous-crystalline interfaces of the polymer composites.
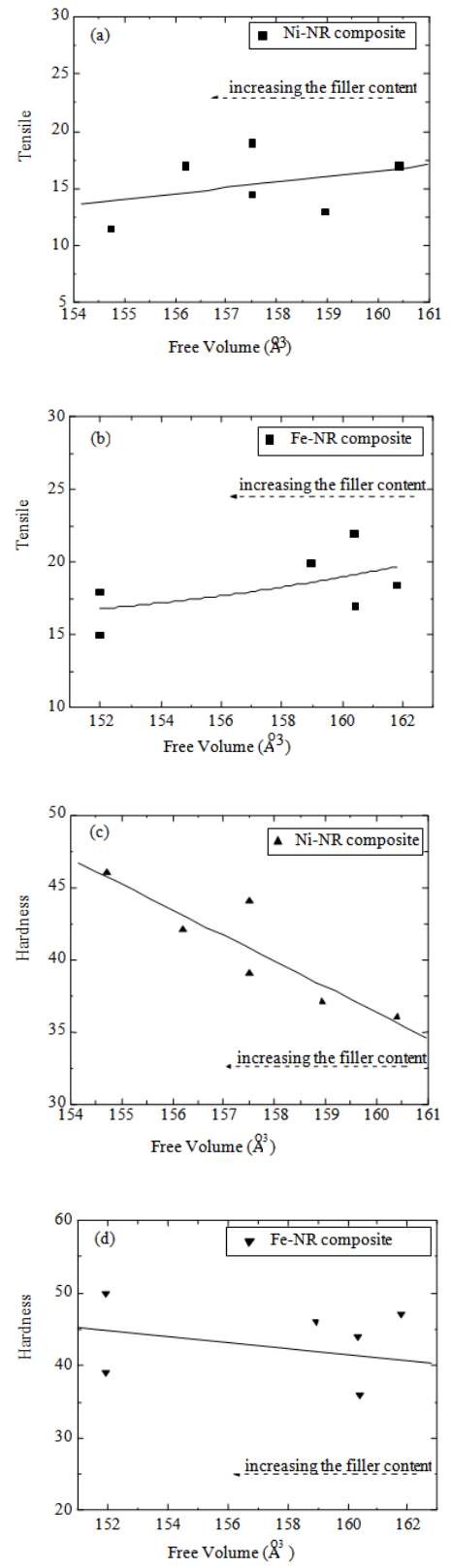

Fig. 5 (a-d): The correlation between the size of free volume holes $\left(\mathrm{V}_{\mathrm{h}}\right)$ and the mechanical properties (tensile strength and hardness)

Correlation between each of the mechanical and electrical properties with the positron annihilation parameters: Because the mechanical and electrical data for the above composites have been published already (El-Nashar et al., 2006), only some results will be given here. Figure 5 a-d exhibits the correlation between the size of free volume holes $\left(\mathrm{V}_{\mathrm{h}}\right)$ and mechanical properties (tensile strength and hardness). A 


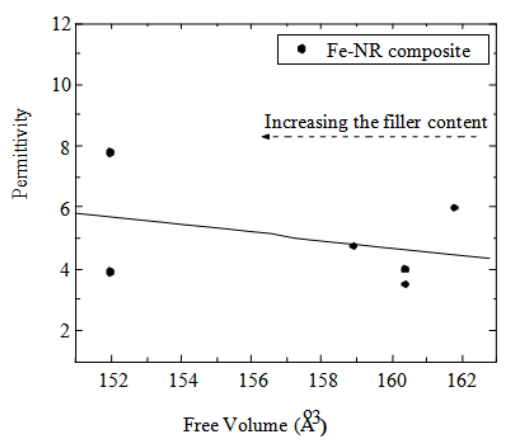

Fig. 6: The correlation between the size of free volume holes and the permittivity $(\dot{\varepsilon})$ as a function of filler loading for both $\mathrm{Ni} / \mathrm{Fe}$-rubber composites

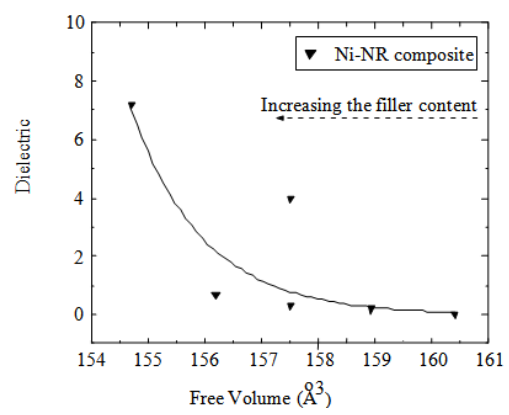

Fig. 7: The correlation between the size of free volume holes and the dielectric loss $(\varepsilon ")$ as a function of filler loading for both $\mathrm{Ni} / \mathrm{Fe}$-rubber composites

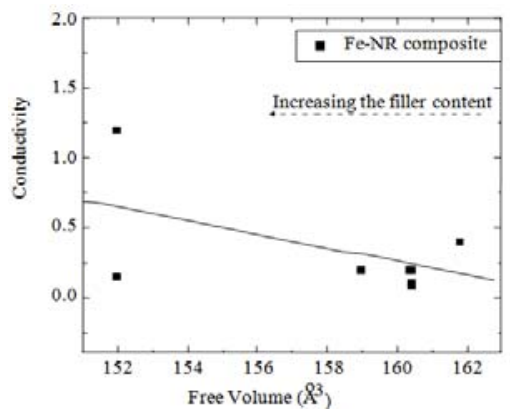

Fig. 8: The correlation between the size of free volume holes and the conductivity $(\sigma)$ as a function of filler loading for both $\mathrm{Ni} / \mathrm{Fe}$-rubber composites

positive correlation is found between the size of free volume holes $\left(\mathrm{V}_{\mathrm{h}}\right)$ and tensile strength for both $\mathrm{Ni} / \mathrm{Fe}-$ rubber composites as shown in Fig. 5a and b. However, the tensile strength of these composites is high at low phr of nano-particles fillers content; and then, it decreases by increasing the filler loading as reported in the previous study (El-Nashar et al., 2006).

Figures 6-8 investigate the correlation between the size of free volume holes and electrical parameters (permittivity, $\dot{\varepsilon}$, dielectric loss, $\varepsilon^{\prime \prime}$ and conductivity, $\sigma$ )

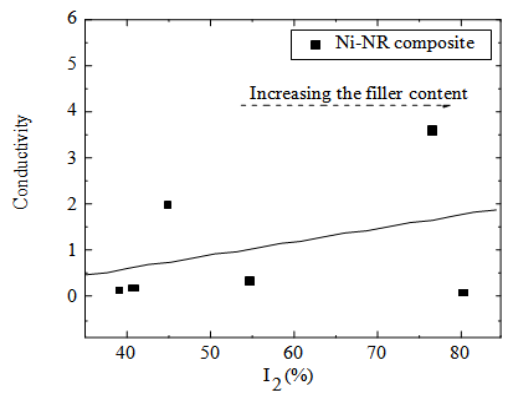

Fig. 9: The intermediate lifetime intensity $\left(I_{2}\right)$ versus the conductivity $(\sigma)$ as a function of filler content (phr)

as a function of filler loading for both $\mathrm{Ni} / \mathrm{Fe}$-rubber composites.

The size of free volume holes for both $\mathrm{Ni} / \mathrm{Fe}-$ rubber composites is negatively correlated with permittivity, $\dot{\varepsilon}$, dielectric loss, $\varepsilon^{\prime \prime}$ and conductivity, $\sigma$, that is $\mathrm{V}_{\mathrm{h}}$ decreases by increasing the phr of filler while $\varepsilon, \varepsilon "$ and $\sigma$ increase by increasing the phr of filler.

In Fig. 9, the intermediate lifetime intensity $\left(\mathrm{I}_{2}\right)$ is plotted versus the conductivity $(\sigma)$ as a function of filler content (phr). Significantly, $\mathrm{I}_{2}$ is attributed to the fraction of free annihilation positron with the free electrons at the polymer matrix-filler interface and this is an indicator of an electric conductivity. So in case of $\mathrm{Ni}$, the larger $\mathrm{I}_{2}$ the greater $\sigma$.

\section{DISCUSSION}

The trend of $\tau_{3}$ in Fig.1 indicates that Ni or Fe filler mainly diffuses into the amorphous region and the concentration $90 \mathrm{phr}$ is thereby an inflection point. Firstly, before the inflection point (at low phr), there is a good filler - interaction due to better dispersion in the rubber matrix (El-Nashar et al., 2009). Secondly, after the inflection point (at high phr), the magnetic property of the filler appears. The interaction of o-Ps with magnetic materials $(\mathrm{Ni}$ and $\mathrm{Fe}$ ) flips the spin of o-Ps electron, which leads to a decrease in $\tau_{3}$. The decrease in $\mathrm{I}_{3}$ as was shown in Fig. 2 is due to the diffusion of filler into rubber matrix. Moreover, the addition of filler changes the crosslinking density of the composites and inhibits o-Ps formation by providing an additional positron interaction mechanism, which competes with Ps formation in the polymer. However, the quenching of o-Ps formation due to $\mathrm{Ni}$ or $\mathrm{Fe}$ ions is observed and this is due to both spin-conversion and oxidation reaction (Schrader and Jean, 1988).

In case of Ni-rubber composites, the decrease in $\tau_{2}$ and increase in $\mathrm{I}_{2}$ (Fig. 4) indicate that the created defects with small size and high concentration in these 
regions are affected by the addition of Ni. In addition, the probability of free positron annihilation $\left(\mathrm{I}_{2}\right)$ is significantly larger than the formation probability of oPs $\left(I_{3}\right)$. The addition of nano-particles fillers create new positron trapping sites at filler-rubber interfaces. This result implies that there are variations in the electron densities at the rubber matrix and interfaces for $\mathrm{Ni}$ rubber composites. Besides, the addition of Fe leads to the creation of defects with constant size and low fraction. This complicated trend in both free positron annihilation and Ps formation in case of Fe-rubber composites is due to rapid oxidation of $\mathrm{Fe}$, which has a great effect on positron annihilation parameters.

It is remarked that the increase of tensile strength, as shown in Fig. 5a and b, at low phr of filler is due to the good filler-rubber interaction as a result of better filler dispersion in the rubber matrix. At high phr of filler, the interaction between filler and the rubber matrix is hindered, resulting in low tensile strength and free volume hole sizes. Moreover, Fig. 5c and d indicates a negative correlation between $\mathrm{V}_{\mathrm{h}}$ and hardness for both $\mathrm{Ni} / \mathrm{Fe}$-rubber composites. Therefore, the addition of $\mathrm{Ni}$ or $\mathrm{Fe}$ nano-particles causes a marked increase in hardness (El-Nashar et al., 2006), reflecting an improved stiffness of the rubber-filler composites. Furthermore, the improved hardness can be attributed to the reinforcement provided by the filler through the stress which has been transferrd to the filler (El-Nashar et al., 2009).

The negative correlations in Figs. 6-8 are due to the polarity of the filler being higher than that of the rubber itself which leads to an increase in electrical parameters and to an inhibition of o-Ps formation. The results imply that the increase of the phr of fillers is connected with an increase in the number of charge carriers and a reduction in the size of free volume hole. According to this logic, the former factor is necessary and useful to electrical properties while the latter factor limits the segmental motion.

Figure 9 shows the correlation between $\mathrm{I}_{2}$ and the conductivity which proves that in the case of Ni-NR composite, the formation of large amounts of microcrystalline boundaries leads to an increase in conducting path or in the number of transfer paths, resulting in better conductivity. While, the addition of Fe to the NR raises the electrical conductivity to some extent and then decreases due to the oxidation process of Fe which leads to a negative correlation between $\mathrm{I}_{2}$ and $\sigma$. These results lead to the conclusion that the investigated composites are considered to be insulating materials as their conductivity values are in the order of an insulator range.

\section{CONCLUSION}

The size of free-volume holes (ranging from 159 $\AA^{3}$ to $155 \AA^{3}$ ) of Ni-rubber composites tends to decrease by increasing the filler content. In contrast, the free-volume hole size of Fe-rubber composites is found to increase (about $159 \AA^{3}$ and stay constant in the range $30-90 \mathrm{phr}$ ) and again decrease (about $154 \AA^{3}$ ) at a higher filler loading of $\mathrm{Fe}$. This behavior could be due to the magnetic property of the iron filler itself. The addition of filler, $\mathrm{Ni}$ or $\mathrm{Fe}$ ions, changes the crosslinking density of the composites and inhibits o-Ps formation; therefore, $I_{3}$ which is a measure of the fraction of free-volume holes decreases by increasing the filler content in rubber. A positive correlation is observed between the size of free volume holes $\left(\mathrm{V}_{\mathrm{h}}\right)$ and tensile strength for both $\mathrm{Ni} / \mathrm{Fe}$-rubber composites. However, this correlation is detected to be negative with permittivity, $\dot{\varepsilon}$, dielectric loss, $\varepsilon$ " and conductivity, $\sigma$. The decrease in $\tau_{2}$ and increase in $I_{2}$ in the case of Ni-rubber composites indicate that the created of defects in the crystalline regions and amorphouscrystalline interfaces are definitely affected by the addition of Ni. The addition of Fe leads to the creation of certain defects with constant size and low fraction. The oxidation process of $\mathrm{Fe}$ leads to a negative correlation between $\mathrm{I}_{2}$ and $\sigma$. In case of $\mathrm{Ni}$, the larger $\mathrm{I}_{2}$ the greater $\sigma$. These results could lead to the conclusion that the investigated composites are considered to be insulating materials as their conductivity values are in the order of an insulator range.

\section{ACKNOWLEDGEMENT}

The researchers are indebted to Dr. D. E. El-Nashar (Polymers and Pigments Department, National Research Centre, Cairo, Egypt) for the samples supply.

\section{REFERENCES}

Ali, A., M. Hosseini and B.B. Sahari, 2010. A review of constitutive models for rubber-like materials. Am. J. Eng. Applied Sci., 3: 232-239. DOI: 10.3844/ajeassp.2010.232.239

Anantharaman, M.R., S. Sindhu, S. Jagatheesan, K.A. Malini and P. Kurian, 1999. Dielectric properties of rubber ferrite composites containing mixed ferrites. J. Phys. D: Applied Phys., 32: 18011810.

Bolonkin, A.A., 2009. Femtotechnology: Nuclear matter with fantastic properties. Am. J. Eng. Applied Sci., 2: 501-514. DOI: 10.3844/ajeassp.2009.501.514 
Brandt, W., 1983. Positron Solid State Physics: Varenna on Lake Como, Villa Monastero. 1st Edn., North-Holland Pub. Co., USA., pp: 710.

Cullity, B.D., 1972. Introduction to Magnetic Materials. 1st Edn., Addison-Wesley Pub. Co., London, ISBN-10: 0201012189, pp: 666.

Dang, Z.M., C.W. Nan, D. Xie, Y.H. Zhang and S.C. Tjong, 2004. Dielectric behavior and dependence of percolation threshold on the conductivity of fillers in polymer-semiconductor composites. Applied Phys. Lett., 85: 97-99. DOI: 10.1063/1.1767951

Dull, T.L., W.E. Frieze, D.W. Gidley, J.N. Sun and A.F. Yee, 2001. Determination of pore size in mesoporous thin films from the annihilation lifetime of positronium. J. Phys. Chem. B, 105: 4657-4662. DOI: 10.1021/jp004182v

Elimat, Z.M., A.M. Zihlif and G. Ragosta, 2008. Study of ac electrical properties of aluminium-epoxy composites. J. Phys. D: Applied Phys., 4: 165408165414. DOI: $10.1088 / 0022-3727 / 41 / 16 / 165408$

El-Nashar, D.E., S.H. Mansour and E. Girgis, 2006. Nickel and iron nano-particles in natural rubber composites. J. Mater. Sci., 41: 5359-5364. DOI: 10.1007/s10853-006-0179-4

El-Nashar, D.E., E. Gomaa and S.L. Abd-El-Messieh, 2009. Study of electrical, mechanical and nanoscale free-volume properties of NBR and EPDM rubber reinforced by bentonite or kaolin. J. Polymer Sci.: Part B: Polymer Phys., 47: 18251838. DOI: $10.1002 /$ polb.21765

Faupel, F., J. Kanzow, K. Guenter-Schade, C. Nagel and P. Sperr et al., 2004. Positron annihilation spectroscopy in polymers. Mater. Sci. Forum, 445446:

219-223.

DOI:10.4028/www.scientific.net/MSF.445446.219

Hussain, F., M. Hojjati, M. Okamoto and R.E. Gorga, 2006. Review article: Polymer-matrix nanocomposites, processing, manufacturing and application: An overview. J. Composite Mater., 40: 1511-1575. DOI: 10.1177/0021998306067321

Jamal, E.M.A., P.A. Joy, P. Kurian and M.R. Anantharaman, 2009. Synthesis of nickelrubber nanocomposites and evaluation of their dielectric properties. Mater. Sci. Eng. B, 156: 2431. DOI: 10.1016/j.mseb.2008.10.041

Jean, Y.C. and G.H. Dai, 1993. Free-volume hole distributions of polymers probed by positron annihilation spectroscopy: Experiences of using the CONTIN program. Nuclear Inst. Meth. Phy. Res. Sec. B: Beam Inter. Mat. Atoms, 79: 356-361. DOI: 10.1016/0168-583X(93)95363-A
Jean, Y.C., 1990. Positron annihilation spectroscopy for chemical analysis: A novel probe for microstructural analysis of polymers. Microchem. J., 42: 72-102. DOI: 10.1016/0026265X(90)90027-3

Kansy, J., 2001. Programs for positron lifetime analysis adjusted to the PC Windows environment. Mater. Sci. Forum, 363-365: 652-654. DOI: 10.4028/www.scientific.net/MSF.363-365.652

Khor, S.F., Z.A. Talib, H.A.A. Sidek, W.M. Daud and B.H. Ng, 2009. Effects of $\mathrm{ZnO}$ on dielectric properties and electrical conductivity of ternary zinc magnesium phosphate glasses. Am. J. Applied Sci., 6: 1010-1014. DOI: 10.3844/ajassp.2009.1010.1014

Makled, M.H., T. Matsui, H. Tsuda, H. Mabuchi and M.K. El-Mansy et al., 2005. Magnetic and dynamic mechanical properties of barium ferritenatural rubber composites. J. Mater. Process. Technol., 160: 229-233. DOI: 10.1016/j.jmatprotec.2004.06.013

Otaigbe, J.U., H.S. Kim and J. Xiao, 1999. Effect of coupling agent and filler particle size on melt rheology of polymer-bonded Nd-Fe-B magnets. Polym. Comps., 20: 697-704. DOI: $10.1002 /$ pc.10393

Pethrick, R.A., 1997. Positron Annihilation--a Probe for Nanoscale Voids and Free Volume. Prog. Polym. Sci., 22: 1-47.

Puska, M.J. and R.M. Nieminen, 1994. Theory of positrons in solids and on solid surfaces. Rev. Mod. Phys., 66: 841-897. DOI: 10.1103/RevModPhys.66.841

Schrader, D.M. and Y.C. Jean, 1988. Positron and Positronium Chemistry. 1st Edn., Elsevier, UK., ISBN-10: 0444430091, pp: 395.

Sindhu, S., M.R. Anantharaman, B.P. Thampi, K.A. Malini and P. Kurian, 2002. Evaluation of a.c. conductivity of rubber ferrite composites from dielectric measurements. Bull. Mater. Sci., 25: 599607. DOI: 10.1007/BF02707892

Tanaka, T., G.C. Montanari and R. Mulhaupt, 2004. Polymer nanocomposites as dielectrics and electrical insulation-perspectives for processing technologies, material characterization and future applications. IEEE Trans. Dielect. Elect. Insul., 11: 763-783. DOI: 10.1109/TDEI.2004.1349782

Urban-Klaehn, J.M. and C.A. Quarles, 1999. Positron annihilation spectroscopy of sandstone and carbonate rocks. J. Applied Phys., 86: 355-363. DOI: $10.1063 / 1.370738$ 
Williams, M.L., R.F. Landel and J.D. Ferry, 1955. The temperature dependence of relaxation mechanisms in amorphous polymers and other glass-forming liquids. J. Am. Chem. Soc., 77: 3701-3707. DOI: 10.1021/ja01619a008

Xiao, J. and J.U. Otaigbe, 2000. Polymer bonded magnets. II. Effect of liquid crystal polymer and surface modification on magneto-mechanical properties. Polym. Comps., 21: 332-342. DOI: $10.1002 /$ pc. 10190
Zhang, B., Y. Feng, J. Xiong, Y. Yang and H. Lu, 2006. Microwave-absorbing properties of de-aggregated flake-shaped carbonyl-iron particle composites at 2-18 GHz. IEEE Trans. Magn., 42: 1778-1781. DOI: 10.1109/TMAG.2006.874188 